\title{
Precarious Employment and Chronic Stress: Do Social Support Networks Matter?
}

\author{
Francesc Belvis ${ }^{1,2, * \mathbb{D}}$, Mireia Bolíbar ${ }^{1,3}$, Joan Benach ${ }^{1,2,4}$ and Mireia Julià $1,5,6$ (D) \\ 1 Research Group on Health Inequalities, Environment, and Employment Conditions (GREDS-EMCONET), \\ Department of Political and Social Sciences, Universitat Pompeu Fabra, 08005 Barcelona, Spain; \\ mireia.bolibar@ub.edu (M.B.); joan.benach@upf.edu (J.B.); mireia.julia.perez@psmar.cat (M.J.) \\ 2 Johns Hopkins University-Universitat Pompeu Fabra Public Policy Center (UPF-PPC), \\ 08005 Barcelona, Spain \\ 3 Department of Sociology, Universitat de Barcelona, 08034 Barcelona, Spain \\ 4 Ecological Humanities Research Group (GHECO), Universidad Autónoma de Madrid, 28049 Madrid, Spain \\ 5 ESIMar (Mar Nursing School), Parc de Salut Mar, Universitat Pompeu Fabra-Affiliated, 08005 Barcelona, Spain \\ 6 SDHEd (Social Determinants and Health Education Research Group), IMIM (Hospital del Mar Medical \\ Research Institute), 08005 Barcelona, Spain \\ * Correspondence: paco.belvis@upf.edu
}

Citation: Belvis, F.; Bolíbar, M.; Benach, J.; Julià, M. Precarious Employment and Chronic Stress: Do Social Support Networks Matter? Int. J. Environ. Res. Public Health 2022, 19, 1909. https://doi.org/10.3390/ ijerph19031909

Academic Editor: Paul B.

Tchounwou

Received: 27 December 2021

Accepted: 3 February 2022

Published: 8 February 2022

Publisher's Note: MDPI stays neutral with regard to jurisdictional claims in published maps and institutional affiliations.

Copyright: (C) 2022 by the authors. Licensee MDPI, Basel, Switzerland. This article is an open access article distributed under the terms and conditions of the Creative Commons Attribution (CC BY) license (https:// creativecommons.org/licenses/by/ $4.0 /)$.

\begin{abstract}
Precarious employment has been identified as a potentially damaging stressor. Conversely, social support networks have a well-known protective effect on health and well-being. The ways in which precariousness and social support may interact have scarcely been studied with respect to either perceived stress or objective stress biomarkers. This research aims to fill this gap by means of a cross-sectional study based on a non-probability quota sample of 250 workers aged 25-60 in Barcelona, Spain. Fieldwork was carried out between May 2019 and January 2020. Employment precariousness, perceived social support and stress levels were measured by means of scales, while individual steroid profiles capturing the chronic stress suffered over a period of a month were obtained from hair samples using a liquid chromatography-tandem mass spectrometry methodology. As for perceived stress, analysis indicates that a reverse buffering effect exists (interaction $\mathrm{B}=0.22, p=0.014$ ). Steroid biomarkers are unrelated to social support, while association with precariousness is weak and only reaches significance at $p<0.05$ in the case of women and 20ß dihydrocortisone metabolites. These results suggest that social support can have negative effects on the relationship between perceived health and an emerging stressful condition like precariousness, while its association with physiological measures of stress remains uncertain.
\end{abstract}

Keywords: chronic stress; precarious employment; social support networks; buffering hypothesis; cortisol; stress biomarkers; health inequalities; social determinants of health

\section{Introduction}

Social support can be defined as the supportive relationships that arise with friends, family members, and others [1]. The relationship between social support levels, stressor events (or a stressful environment), and health or wellbeing outcomes has been studied largely by behavioural and medical scientists, under the assumption that social support provides some kind of protection against the psychological or physiological disorders produced by chronic stress. One of the remaining research questions on this issue is the specific nature of this relationship, where the main effects model (that is to say, stressor and social support acting independently on health status, negatively in the first case and positively in the second) is often opposed to the "buffering hypothesis" [2]. While the buffering hypothesis posits that the positive relationship between social support and health is due, only or primarily, to the protection that social support offers persons from the potentially pathogenic influence of stressful events, the main effects model proposes that 
social resources have a beneficial effect irrespective of whether persons are under stress. Both theories also differ in respect of the pathways through which participation in social networks can affect psychological well-being [3].

The relationship between stressful events and social support has also been extensively tested for stressful work-related situations (in relation to both the main effects model and the buffering hypothesis paradigm) [4], such as unemployment [5-8], job searches [9], or intense work [10], but it has only very recently been tested for employment precariousness [11]. Although there is still no full consensus on its definition, precarious employment might be considered a multidimensional construct encompassing dimensions such as employment insecurity, individualized bargaining relations between workers and employers, low wages and economic deprivation, limited workplace rights and social protection, and powerlessness to exercise workplace rights [12]. In recent decades, and also due to different economic crises, technological changes, and policies that have weakened unions' collective bargaining power, there has been an increase in the flexibility of employment conditions with profound changes that have led to the precarization of employment conditions $[13,14]$. Employment precariousness is particularly prevalent among the most vulnerable social groups in the labor market, like women, immigrants, the working class, and young workers. Moreover, early evidence suggests that the recent COVID-19 pandemic has increased precarious employment and that precarious workers will we exposed to serious stressors [15].

Certainly, precarious employment has been identified as a relevant social determinant of health and health inequalities that has a strong impact on self-perceived health, including mental health [12]. Among the pathways and mechanisms linking these two outcomes, several are related to increased stress. Workers under situations of precarious employment often face greater demands or have less control over the work process and experience social isolation [16] and a lack of support [17]. These experiences have been identified as powerful social stressors [16], which in turn can be linked to adverse health and wellbeing outcomes [18]. More generally, precarious jobs may limit workers' control over their professional and personal lives, leading to experiences of job insecurity, feelings of betrayal and injustice, feelings of powerlessness and being out of control, a lack of future opportunities, or a lack of professional identity [19-22]. As for precarious employment, there is a suspicion that its relation to health outcomes may be affected by a deleterious impact on the social support networks [23]. Individuals in a more precarious situation tend to have smaller and less diverse networks [24] and, given the tendency to socialize with people from similar socio-economic situations [25], the networks of those in a precarious situation also tend to be less capable of providing resources. This will not only result in lower levels of social support for precarious workers, but also the buffering capacity of the support received will be eroded.

A second gap in social epidemiological research on work stress events and social support networks is that it is mostly focused on perceived measures of health. This may be a consequence of the narrow division among disciplines that has led researchers to consider social causes aside from the biological ones together with the difficulties in collecting large-scale reliable biological data [26]. This has begun to change and in recent years, much attention has been given to the study of hair cortisol as a biomarker of chronic stress. Cortisol is a glucocorticoid hormone released after stimulation of the hypothalamicpituitary-adrenal axis (HPA), which is activated by stress and is involved in the body's response to stress [27]. In contrast to other sources such as urine, saliva, and plasma, which provide one-off momentary information about the individual's hormonal status and are highly affected by different factors such as the circadian rhythm or fear of needles, determining the amount of cortisol in hair would provide information about the chronic status of the steroid hormones [28].

Literature specifically regarding the relationship between social support and hair cortisol is extremely scarce, and the results are also contradictory. There is a doctoral thesis [29] that is dedicated to studying the relationship of psychosocial factors and high 
cortisol concentrations (HCC), including social support measured in three dimensions: its assessment, feelings of belonging, and tangible support. Using a sample of 165 workers, the relationships were found to be inverse to what was hypothesized by the author herself, given that greater social support has been directly related to higher levels of HCC. The study by [30] also considers the role of social support as a buffer against stressful situations. Using a sample of 71 patients with bipolar disorder, the authors first positively correlated the number of negative events that occurred in the subjects' life with cortisol levels in the latter's hair, showing how this relationship is totally minimized by self-perceived instrumental and emotional social support.

Considering the scarcity of studies and uncertainties highlighted in this section, the objective of this paper is twofold: (a) to test the main effect and possible moderator role of social support on the relationship between precarious employment, understood as a stressful factor, and perceived stress levels, and (b) to apply the same analytical framework to biological markers of chronic stress.

\section{Materials and Methods}

\subsection{Study Design, Sample and Variables}

This is a cross-sectional study corresponding to the second phase of a three-phase sequential mixed research design oriented to identify the pathways and mechanisms explaining the well-established relationship between precarious employment and health [23]. In the previous phase, secondary analysis of the Survey on Workers and the Unemployed of Barcelona (EPYPB, 2017-2018) was used to map the sociogeographical distribution of precarious employment in the city of Barcelona. This information was used to implement a non-probabilistic sampling strategy of $n=255$ cases based on proportional quotas based on sex, age group, place of origin (born in Spain vs. born abroad), and the socioeconomic level of the district of residence (medium, medium-high, or high vs. medium-low and low-income districts). Due to practical and financial constraints, studies involving hair cortisol are unlikely to consist of large samples. The overall sample sizes in a systematic review of studies addressing hair cortisol and chronic stress or mental health relationship range from under $n=100$ to $n=395$ at a maximum [28], while the sample in [31] is unusually large $(n=760)$. Therefore, our sample was designed to show how cortisol in hair (and other related biomarkers of the HPA axis) are distributed throughout the whole range of experiences of precarious employment previously identified in Barcelona and to unravel the explanatory power of the pathways and mechanisms linking precariousness to health, in particular, social support. Nonetheless, under the assumptions of an alpha risk of 0.05 and a beta risk below 0.2 (80\% power) in a two-sided test and with a sample loss rate of $0 \%$, our sample size will allow us to estimate correlation coefficients of 0.175 . Participants were recruited from the pool of participants in the EPYPB within the selected age range of people who had agreed to being contacted again for future studies and specifically for this project $(n=1210)$. Also, in order to offset the bias of this subsample toward profiles with higher levels of education and income, the abovementioned recruitment strategy was complemented with 40 individuals contacted through social and labor organizations that work with groups of precarious workers, with a slight overrepresentation of immigrant women. Inclusion criteria were: (i) being a salaried worker or bogus self-employed worker serving a single employer, (ii) being between 24 and 60 years old, (iii) living independently in Barcelona (i.e., young people living with their parents were excluded), (iv) the length of hair at the back of the head being at least one centimeter, and (v) not having taken holidays within the month prior to the interview. Exclusion criteria were: (i) having taken corticosteroids within the month prior to the interview, (ii) being diagnosed with an adrenal disease, and (iii) being pregnant, due to possible alterations in cortisol levels.

The questionnaire collected information about the main concepts involved in the present analysis, including the sociodemographics used as control variables. Employment precariousness was measured by means of the Precarious Employment Scale (EPRES), a validated instrument [32]. As for social support, the Duke-UNK-11 Functional Social 
Support scale [33] was used. This is a perceived social support scale that has the advantages of being multidimensional, standing out for its simplicity and brevity, and having also been validated in Spain [34]. Perceived stress levels were determined by means of the Perceived Stress Scale (PSS), a 14-item measure of experienced levels of stress [35]. Upon completing it, a sample of participants' hair equivalent to a lock of hair of the thickness of a pen (between $\sim 30$ and $50 \mathrm{mg}$ ) was taken by the previously trained interviewers from the back of the head using scissors cutting as close to the skin as possible. The first centimeter of the lock of hair that is in contact with the scalp is the biological material subjected to laboratory analysis. Since hair grows about one centimeter per month, the selection of this segment implies that the level of chronic stress accumulated over the month prior to sampling can be identified. The steroids profile (simultaneous levels of cortisol and other steroid metabolites) was measured in hair samples through a validated protocol based on liquid chromatography-tandem mass spectrometry (LC-MS/MS) [36]. Briefly, samples were washed with dichloromethane and shredded with a ball mill. After weighting (c.a. $50 \mathrm{mg}$ ) and adding the internal standard, steroids were extracted with methanol. Analytes were preconcentrated using a liquid-liquid extraction with ethyl acetate and determined by LC-MS/MS using an Acquity UPLC system (Waters Associates, Milford, MA, USA) coupled with a triple quadrupole (TQS Micro) mass spectrometer provided with an orthogonal Z-spray-electrospray interface (ESI) (Waters Associates). Steroids were quantified by external calibration using labelled steroids as internal standards. Concentrations, normalized by the weight for each sample, were expressed as nanogram steroid/milligram hair (ng/mg). Up to seven biomarkers of the HPA axis, which plays a central role in the physiological response to stress, were considered in this research: Cortisol and their metabolites $20 \alpha$-dihydrocortisol $(20 \alpha \mathrm{DHF})$ and $20 ß$-dihydrocortisol (20ßDHF); Cortisone and their metabolites $20 \alpha$-dihydrocortisone $(20 \alpha \mathrm{DHE})$ and $20 ß$-dihydrocortisone (20ßDHE); and A_11dehydrocorticosterona (11-DHC). Many of these substances are closely related isomers. Cortisone is a metabolite from cortisol with a similar function and also correlated with stress levels in the subject, and A_11dehydrocorticosterona is an endogenous corticosteroid related to cortisone and corticosterone.

\subsection{Statistical Analysis}

Variables in the research and their relationships were described by means of univariate and bivariate statistics, and their statistical properties were investigated. Biomarker variables were log-transformed in order to normalize their highly skewed distributions.

A linear model predicting perceived stress from precariousness and social support levels was adjusted to the data, with sex and age group as control variables. The former main effect model was compared to a second one allowing for an interaction between precariousness and social support to test the existence of a buffering effect. Interaction effects were studied by graphical means, and the Johnson-Neyman method $[37,38]$ was used to establish the range of values of social support within which precariousness significantly impacts stress levels.

Similar models were adjusted for each of the available biomarkers. In this case, however, Body Mass Index (BMI) was added as a control variable, as evidence exists that body weight partly determines these biological outcomes [39]. Moreover, an additional interaction between sex and precariousness levels was allowed, as bivariate analysis stratified by sex (Figure A1) suggested that the relationship between precariousness and some biomarkers was stronger in the case of women.

The main analyses were performed with the $R$ environment and the $R$ version of the PROCESS macro v.4.0 [40]. Interactions were further investigated with the homonymous $\mathrm{R}$ package [41], and the linear model regression assumptions were tested by means of the gvlma package based on [42]. 


\section{Results}

\subsection{Descriptives}

Information for the $n=255$ individuals in the sample is almost complete in the variables considered except for a few cases in some biomarkers (Table 1). Observation of ranges and quartiles reveals that the distribution of biomarkers is highly positively skewed.

Table 1. Descriptives of the variables in the research.

\begin{tabular}{|c|c|c|c|c|c|c|}
\hline Variables & Range & $\begin{array}{c}\text { 1st } \\
\text { Quartil }\end{array}$ & Median & Mean & $\begin{array}{c}\text { 3rd } \\
\text { Quartil }\end{array}$ & Missing \\
\hline \multicolumn{7}{|l|}{ Outcomes } \\
\hline Perceived Stress Scale (PSS scale) & $1-44$ & 19.00 & 24.00 & 24.34 & 30.00 & 0 \\
\hline Cortisol (ng/mg) & $1.12-70.27$ & 4.76 & 6.88 & 9.75 & 11.71 & 4 \\
\hline $20 \alpha$-dihydrocortisol ( $20 \alpha \mathrm{DHF}, \mathrm{ng} / \mathrm{mg})$ & $0.10-7.60$ & 0.35 & 0.67 & 1.01 & 1.14 & 5 \\
\hline 20ß-dihydrocortisol (20ßDHF, ng/mg) & $1.01-23.12$ & 2.85 & 4.05 & 5.05 & 5.98 & 0 \\
\hline Cortisona $(\mathrm{ng} / \mathrm{mg})$ & $3.08-128.05$ & 19.47 & 25.89 & 30.32 & 35.17 & 0 \\
\hline $20 \alpha$-dihydrocortisone $(20 \alpha \mathrm{DHE}, \mathrm{ng} / \mathrm{mg})$ & $1.57-61.98$ & 5.15 & 7.17 & 9.62 & 11.54 & 0 \\
\hline $20 ß$ dihydrocortisone (20ßDHE, ng/mg) & $1.31-36.79$ & 3.57 & 5.02 & 6.41 & 7.42 & 0 \\
\hline \multicolumn{7}{|l|}{ Predictors } \\
\hline Precariousness (EPRES scale) & $0.06-3.01$ & 0.61 & 0.96 & 1.03 & 1.39 & 0 \\
\hline Social Support (DUFSS scale) & 19-55 & 41 & 46 & 44.48 & 50.3 & 0 \\
\hline \multicolumn{7}{|l|}{ Adjustment variables } \\
\hline Woman & $0-1$ & --- & -- & 0.51 & -- & 0 \\
\hline Age > 34 (years) & $0-1$ & --- & --- & 0.74 & --- & 0 \\
\hline Body Mass Index $\left(\mathrm{kg} / \mathrm{m}^{2}\right)$ & $16.61-42.91$ & 22.23 & 24.51 & 25.04 & 27.17 & 0 \\
\hline
\end{tabular}

The analysis of bivariate correlations between the variables in this study shows very clear patterns: (a) precariousness, social support, and perceived stress are moderately correlated with one another; (b) biomarkers are strongly positively correlated with one another; (c) the former groups are virtually unrelated, with the exception of precariousness, which is weakly positively correlated with some biomarkers; and (d) control variables show scattered weak positive and negative correlations with groups of variables (a) and (b) (Figure 1).

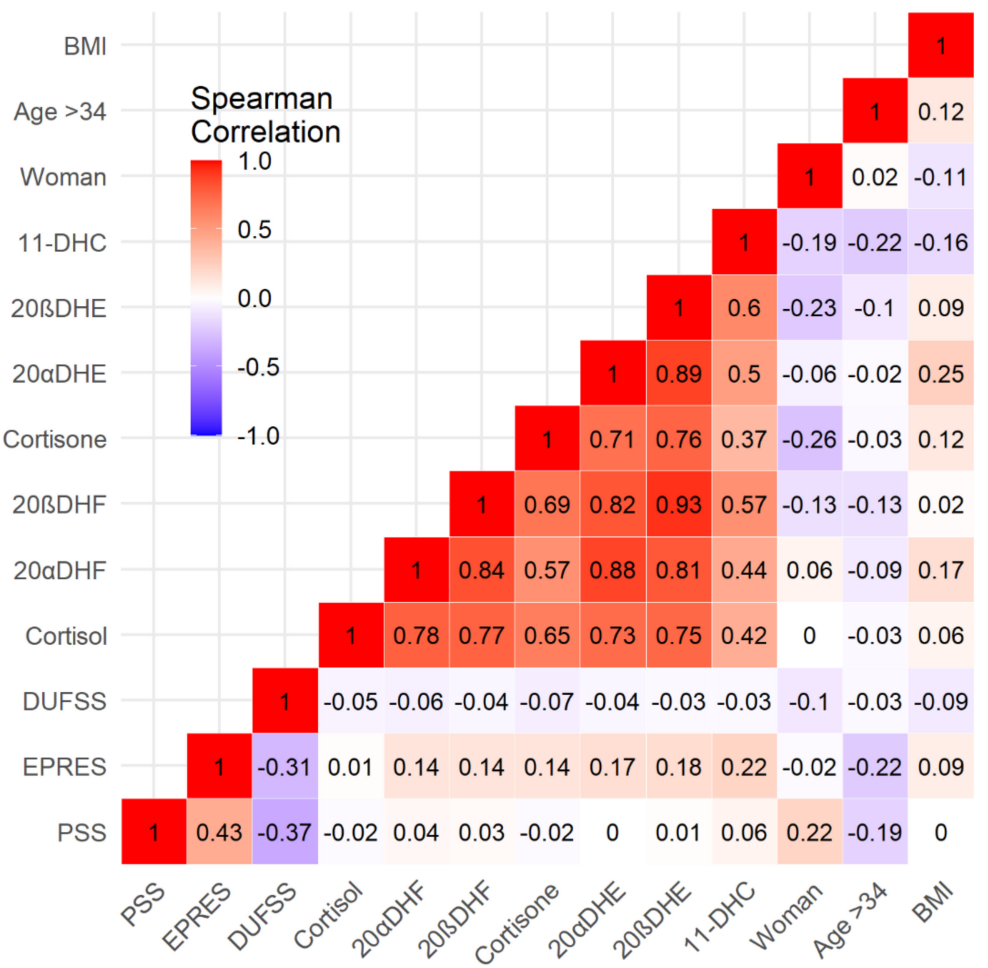

Figure 1. Bivariate Spearman correlations between the variables in study. 


\subsection{Perceived Stress}

Table 2 shows the main effects (1) and interaction (2) regression results of social support and employment precariousness predicting perceived stress levels. Estimated coefficients are very similar, and for this reason we will only comment on model (2) outcomes. The main effect of EPRES is positive and significant $(B=4.32, p<0.001)$, indicating that higher levels of precariousness are associated with higher stress, while the main effect of social support is negative and significant $(B=-0.27, p<0.001)$, meaning that higher social support is related to lower levels of stress. The interaction coefficient of the former factors is also significant and positive $(B=0.22, p<0.014)$ and represents an increase of 0.0151 in the determination coefficient $\left(\mathrm{R}^{2}\right)$ of model (2) respect model (1). Additionally, being a woman significantly increases stress levels $(B=3.45, p<0.001)$, while being above the age of 34 years old significantly decreases them $(B=-2.27, p<0.019)$. Overall the predicting capacity of the model $\left(\mathrm{R}^{2}=0.304\right)$ is acceptable, and no significant departures from linear regression assumptions were found (Table 2 ).

Table 2. Main effects (1) and interaction (2) regression results of social support and employment precariousness predicting perceived stress levels.

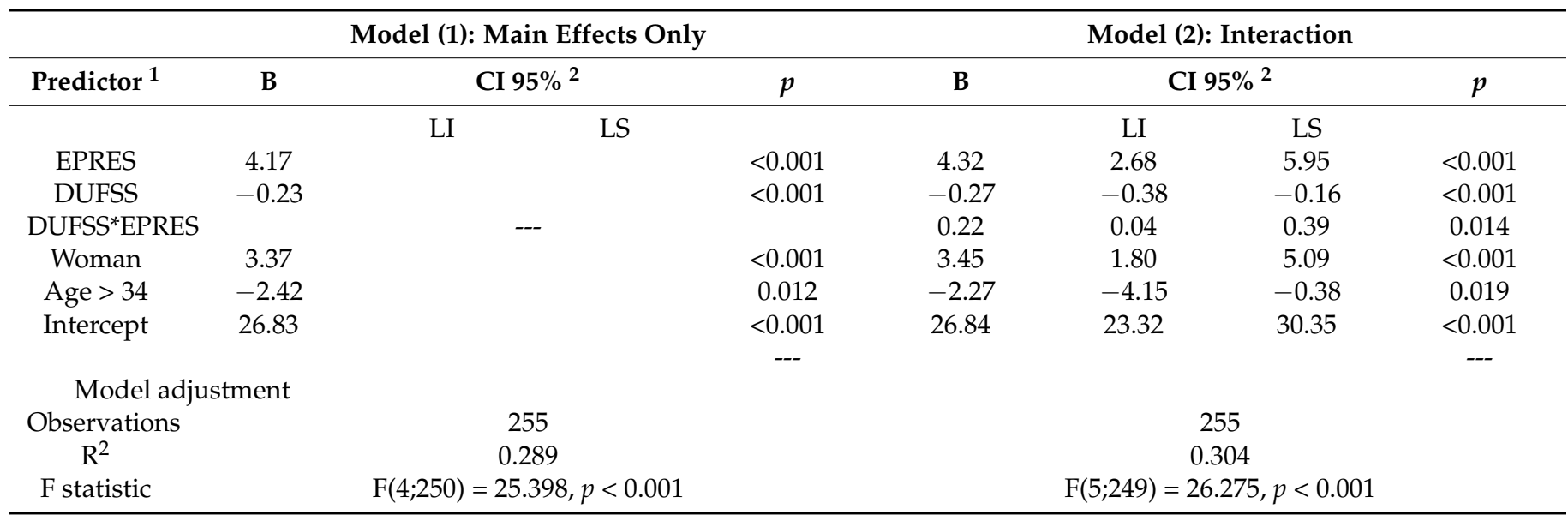

${ }^{1}$ Mean-centered values of EPRES and DUFSS scales were used. ${ }^{2}$ A heteroscedasticity consistent standard error (HC3) and covariance matrix estimator were used.

Further analyses have been carried out on the interaction between employment precariousness and social support. Figure 2a shows that the impact of the precariousness level on the stress level decreases as social support increases for all levels of precariousness, but the moderator effect of social support is greater at low precariousness levels $(-1$ SD, dotted blue line) than at the mean (0 SD, dashed violet line) or high levels of precariousness (1 SD, solid red line). Specifically, the slope of DUFSS is B $=-0.391, p<0.001$ in the case of low precariousness, $\mathrm{B}=-0.270, p<0.001$ in the case of medium precariousness, and $\mathrm{B}=-0.149$, $p<0.05$ in the case of high precariousness. 

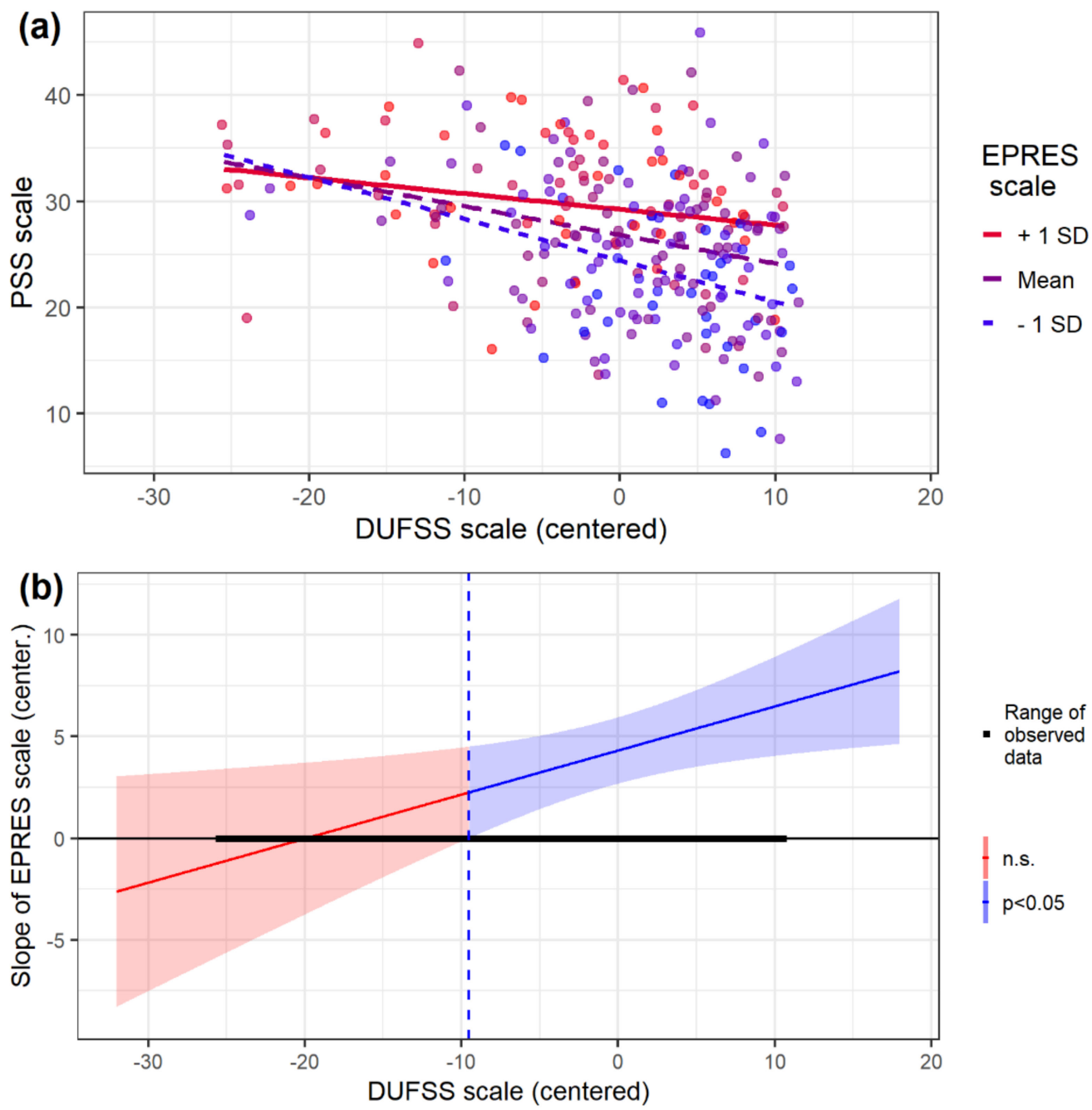

Figure 2. Plot of interaction of EPRES and DUFSS scales (a) and region of significance of the EPRES slope (b).

According to the Johnson-Neyman method (Figure 2b), the effect of precariousness on stress is significantly positive $(p<0.05)$ outside the region determined by the (centered) values of social support $[-96.55,-9.53]$. As can be seen, most of the observed cases in our sample $(87.5 \%)$ are above this -9.53 value of social support (vertical blue dashed line).

\subsection{Biomarkers of Chronic Stresss}

The interaction between precariousness and social support unveiled in the perceived stress analysis is completely absent when biomarkers are used as an outcome in the regressions (Tables 3 and $\mathrm{A} 1$ for $20 \alpha \mathrm{DHE}$ biomarker). 
Table 3. Regression results of social support and employment precariousness interaction model predicting different biomarker levels.

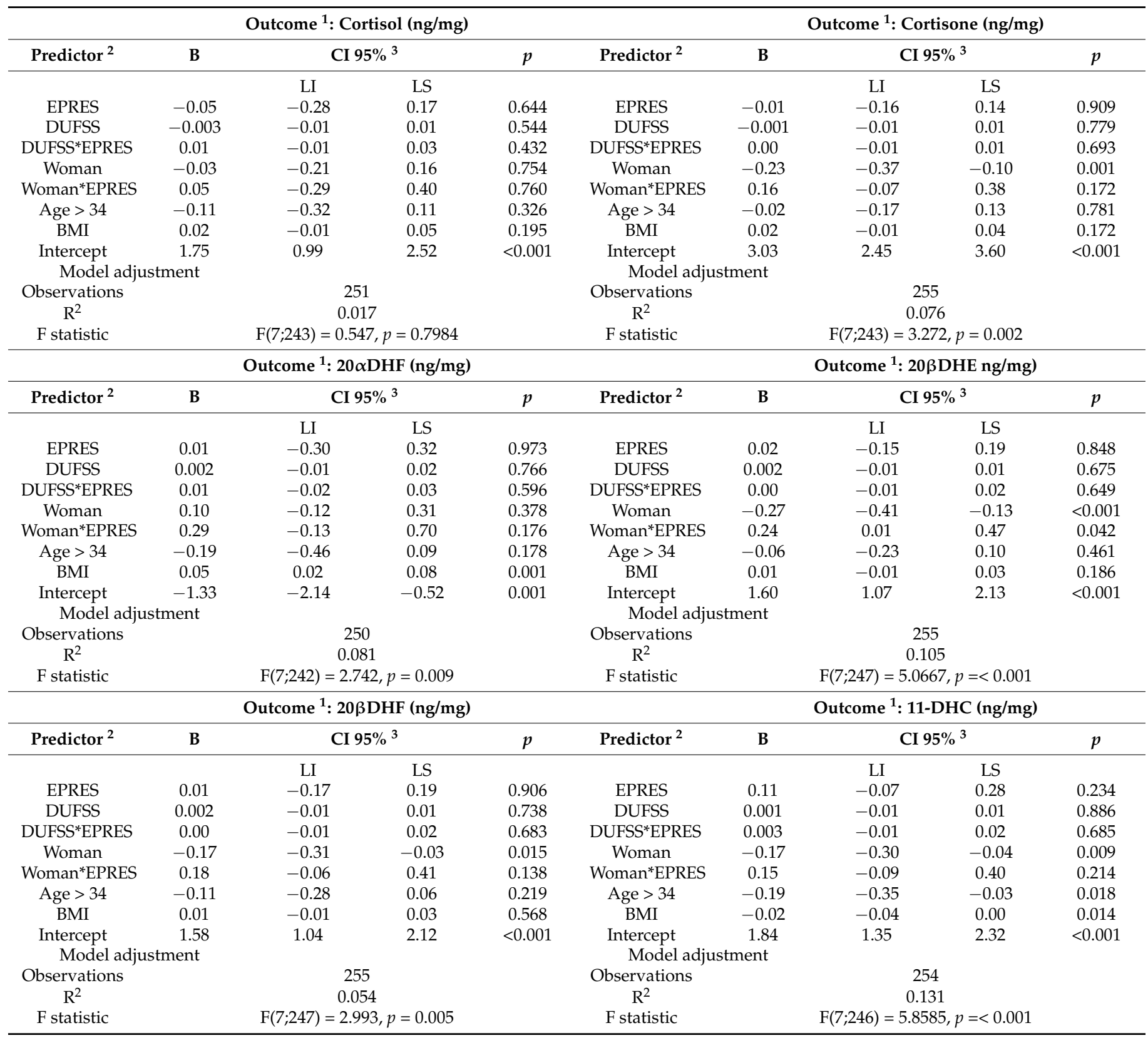

${ }^{1}$ All outcomes have been transformed into logarithms to correct skewness. ${ }^{2}$ Mean-centered values of EPRESS and DUFSS scales were used. ${ }^{3}$ A heteroscedasticity consistent standard error (HC3) and covariance matrix estimator were used.

In fact, there is not a single indication that social support influences biomarkers at all. As for Cortisol, neither the main effect nor the interactions are significant for the predictors considered, and the whole model is useless $\left(\mathrm{R}^{2}=0.017, p=0.7984\right)$. The BMI is the only significant predictor in the case of $20 \alpha \mathrm{DHF}(\mathrm{B}=0.05, p=0.001)$, while being a woman predicts $20 \beta \mathrm{DHF}$ and cortisone levels $(\mathrm{B}=-0.17, p=0.015$ and $\mathrm{B}=-0.23, p=0.001$, respectively). Higher BMI, being a woman, and being older are also negatively associated with 11-DHC levels $(\mathrm{B}=-0.17, p=0.009 ; \mathrm{B}=-0.19, p=0.018$ and $\mathrm{B}=-0.02, p=0.014$, respectively). Finally, there is little evidence that precariousness influences $20 \alpha \mathrm{DHE}$ and 20ßDHE biomarkers levels, as the interaction between EPRES and sex appears to be significant $(\mathrm{B}=0.24, p=0.071$ Table $\mathrm{A} 1$, and $\mathrm{B}=0.24, p=0.042$, respectively). 
Further analyses have been carried out concerning the interaction between sex and precariousness on the $20 \beta \mathrm{DHE}$ biomarker, in which this interaction was significant at $p<0.05$. Figure 3 shows that $20 \beta$ DHE levels are practically unaffected by precariousness in men (blue dashed line), whereas a positive association does exist for women (red solid line). Specifically, the slope of EPRES in the case of men is $\mathrm{B}=0.017, p=0.850$, whereas in the case of women it is $\mathrm{B}=0.257, p<0.01$.

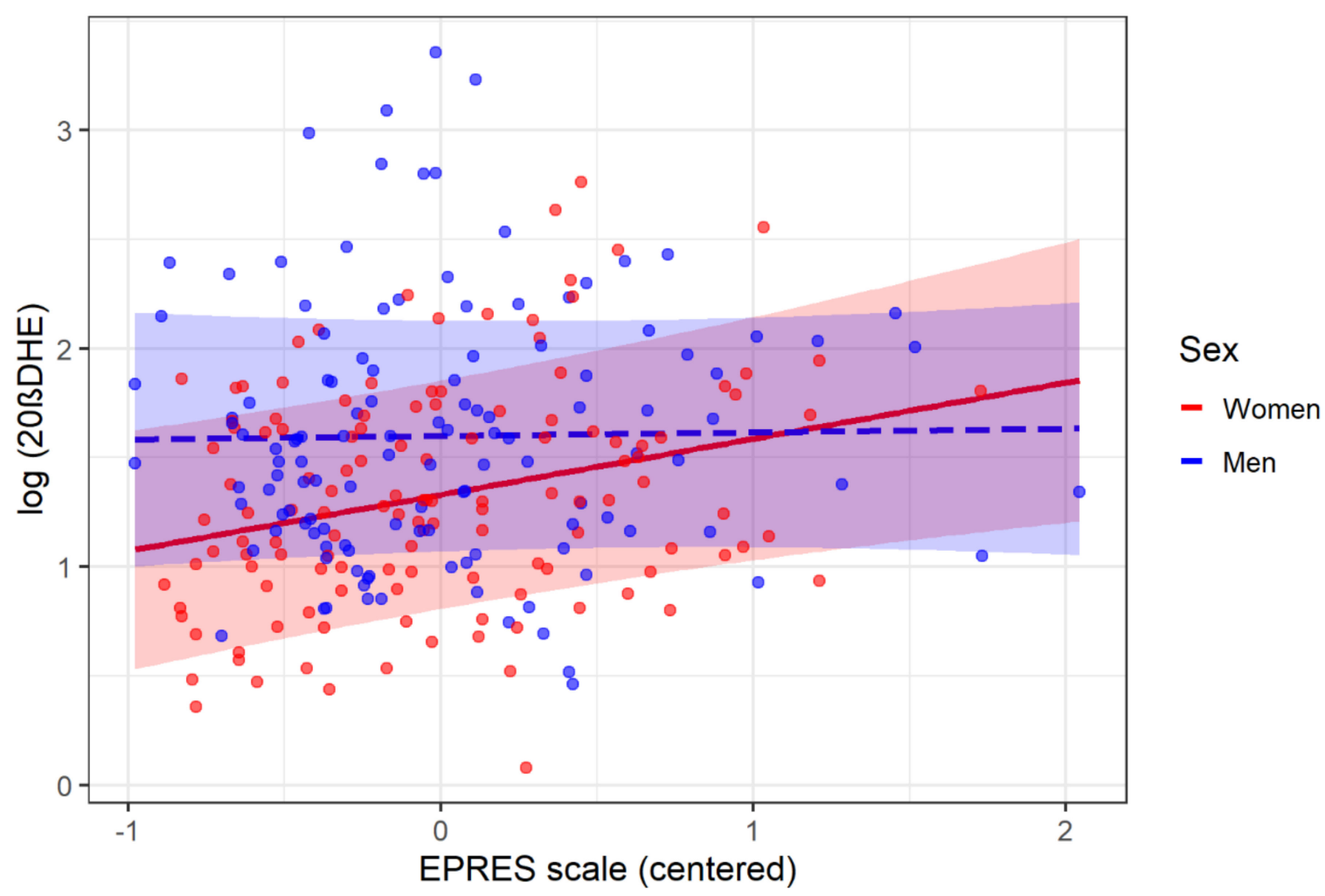

Figure 3. Plot of the interaction effect between sex and EPRES on 20ßDHE biomarker.

\section{Discussion}

In this paper, we have studied the effect of employment precariousness and social support on both perceived stress and steroid profiles. As for the first outcome, expectations that perceived stress will be associated positively with precariousness and negatively with social support have been confirmed. This result is in line with most cross-sectional research that has tested the main effects of stressors and social support on health outcomes [43] and work-related stress events and social support specifically $[5,11]$. We have also found that workers who are more precarious have lower levels of social support than less precarious ones (i.e., both factors are negatively correlated). Moreover, the overall effect of precariousness and social support on perceived stress is not simply summative, given that a significant interaction effect between the two factors was found. However, the interaction has little explanatory power and, more importantly, it is against the expectations of the buffering model put forward by Cohen and Wills, as the reduction of stress levels as social support increases is less intense at higher levels of the stressor than at the lower ones. This result is known as the "reverse buffering effect" and has already been described in relation to work stressors $[44,45]$. The reverse buffering effect occurs either because "excessive" social support undermines individuals' confidence in their capacity to overcome the stresses or because (given that social support involves communication) sharing negative experiences or perceptions could reinforce stressors $[46,47]$. The latter hypothesis could be well adapted to the case of employment precariousness, given the tendency to socialize with people from similar socio-economic situations (as theorized in the Introduction) and that closer providers of social support frequently include dependent persons who may represent a 
further source of concern for the precarious worker. Unfortunately, this finding is based on our small sample size. Therefore, a straightforward recommendation derived from our study for further research is the testing of the buffering hypothesis concerning employment precariousness and social support on a general population representative sample size, something that, to our knowledge, has not been done but is perfectly feasible if a perceived health outcome is chosen. In fact, this approach was used to test the buffering hypothesis on unemployment, although in this case direct and not reverse buffering effects of social support were found [8]. Moreover, the moderate correlation between precariousness and social support suggests that alternative causal relationships between the variables (a mediator role of social support, in particular) could be tested.

Social support proved to be completely unrelated to the set of steroid biomarkers. As for precariousness, it is also unrelated to most of them, including cortisol. These results are in line with [39], which failed to reveal reliable HCC associations with psychosocial variables, and confirm the difficulty of moving from the psychosocial dimension to the biological one in research into the mechanisms through which social conditions affect health. Even biologically grounded variables such as sex, age, and BMI present a weak and unstable association with the biomarkers. It can be concluded there is still much work to be done in order to understand which factors are influencing these cortisol metabolites levels, or even their very meaning in relation to stress, before moving to more sophisticated causal analysis like that attempted here. Other limitations of our research are related to its cross-sectional design, which is prone to unobserved heterogeneity effects between individuals, and the limited sample size, which advises against adjusting for a greater number of variables.

From a positive perspective, and given the former, the significant interactions found between precariousness and sex in predicting levels of the $20 \alpha \mathrm{DHE}$ and $20 \beta \mathrm{DHE}$ biomarkers for women must be given value. Analysis in progress suggests that specific dimensions of the EPRES scale are more clearly related to certain biomarkers that are different depending on sex.

\section{Conclusions}

Precarious employment proved to be a risk factor for increased stress. Moreover, perceived social support levels are lower for workers with higher precariousness, which may be due to their weakened social networks. Our results also suggest that social support can intensify rather than buffer the impact of precarious employment on perceived stress, although this effect is small in statistical terms. This could be explained because the sharing of negative experiences or perceptions within the worker's social support networks could reinforce stressors. These findings could not be replicated when the former analytical framework was applied to a set of steroid biomarkers. Social support was found to be completely unrelated to them, while precarious employment was weakly related to certain biomarkers in the case of women. More research is needed to understand how these social factors may translate into steroid profiles in hair.

Author Contributions: M.B. and F.B. conceived and designed the study. F.B. undertook the statistical analysis. M.J. and F.B. reviewed the literature. M.J. and F.B. prepared the original draft. All authors (M.J., M.B., F.B. and J.B.) contributed substantially to the interpretation of data. All authors have read and agreed to the published version of the manuscript.

Funding: This work was supported by the Spanish Ministry of Science, Innovation and Universities under the research grant "Precariedad laboral y estrés: factores sociales con impacto biomédico", ref. CSO2017-89719-R funded by the Agencia Estatal de Investigación (AEI) and the European Regional Development Fund (ERDF), EU.

Institutional Review Board Statement: The study was conducted according to the guidelines of the Declaration of Helsinki and approved by the Institutional Commission for Ethical Review of Projects (CIREP) of the Universitat Pompeu Fabra (protocol code approval number CIREP nr.0079, 20.07.2018). 
Informed Consent Statement: Informed consent was obtained from all the subjects involved in the study.

Data Availability Statement: The data presented in this study are available in anonymized form upon request from the corresponding author. The data are not publicly available due to their containing information that could compromise the privacy of the research participants.

Conflicts of Interest: The authors declare no conflict of interest.

\section{Appendix A}

These analyses were not included in the main text and are presented as additional material:

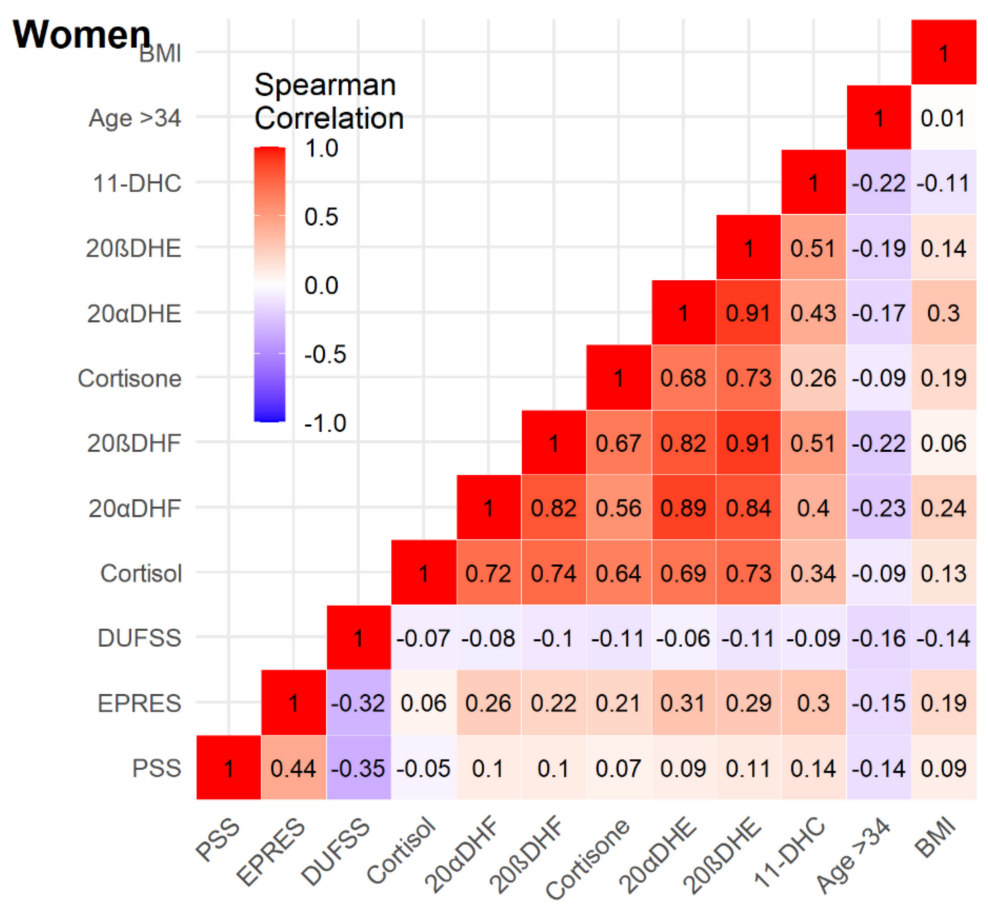

Men

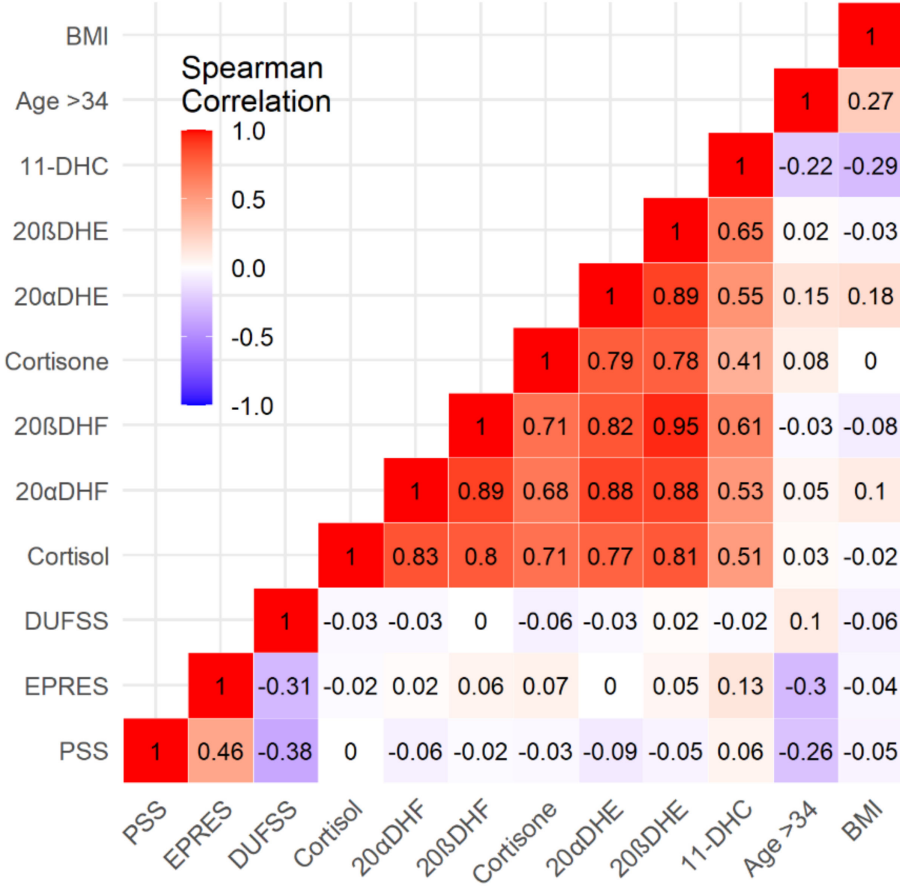

Figure A1. Bivariate Spearman correlations between the variables in study stratified by Sex. 
Table A1. Regression results of social support and employment precariousness interaction model predicting $20 \alpha \mathrm{DHE}$ biomarker.

\begin{tabular}{|c|c|c|c|c|}
\hline \multirow[b]{2}{*}{ Predictor $^{2}$} & \multicolumn{4}{|c|}{ Outcome $^{1}:$ 20 $\alpha$ DE (ng/mg) } \\
\hline & B & \multicolumn{2}{|c|}{ CI $95 \%{ }^{3}$} & $p$ \\
\hline & & LI & LS & \\
\hline EPRES & 0.01 & -0.19 & 0.20 & 0.935 \\
\hline DUFSS & 0.004 & -0.01 & 0.01 & 0.439 \\
\hline DUFSS*EPRES & 0.00 & 0.02 & 0.01 & 0.989 \\
\hline Woman & -0.07 & -0.22 & 0.07 & 0.324 \\
\hline Woman*EPRES & 0.25 & -0.02 & 0.52 & 0.071 \\
\hline Age $>34$ & -0.04 & -0.22 & 0.14 & 0.667 \\
\hline BMI & 0.04 & 0.02 & 0.06 & $<0.001$ \\
\hline $\begin{array}{l}\text { Intercept } \\
\text { Model }\end{array}$ & 1.11 & 0.56 & 1.66 & $<0.001$ \\
\hline \multicolumn{5}{|l|}{ Adjustment } \\
\hline Observations & \multicolumn{4}{|c|}{255} \\
\hline $\mathrm{R}^{2}$ & \multicolumn{4}{|c|}{0.119} \\
\hline F statistic & \multicolumn{4}{|c|}{$\mathrm{F}(7 ; 247)=3.9196, p<0.001$} \\
\hline
\end{tabular}

${ }^{1}$ All outcomes have been transformed into logarithms to correct skewness. ${ }^{2}$ Mean-centered values of EPRESS and DUFSS scales were used. ${ }^{3}$ A heteroscedasticity consistent standard error (HC3) and covariance matrix estimator were used.

\section{References}

1. Friis, R.H.; Sellers, T. Epidemiology for Public Health Practice; Jones \& Bartlett Learning: Burlington, MA, USA, 2020.

2. Cohen, S.; Wills, T.A. Stress, Social Support, and the Buffering Hypothesis. Psychol. Bull. 1985, 98, 310-357. [CrossRef] [PubMed]

3. Kawachi, I. Social Ties and Mental Health. J. Urban Health 2001, 78, 458-467. [CrossRef] [PubMed]

4. Viswesvaran, C.; Sanchez, J.I.; Fisher, J. The Role of Social Support in the Process of Work Stress: A Meta-Analysis. J. Vocat. Behav. 1999, 54, 314-334. [CrossRef]

5. Axelsson, L.; Ejlertsson, G. Self-Reported Health, Self-Esteem and Social Support among Young Unemployed People: A Population-Based Study. Int. J. Soc. Welf. 2002, 11, 111-119. [CrossRef]

6. Craveiro, D. The Role of Personal Social Networks on Health Inequalities across European Regions. Health Place 2017, 45, $24-31$. [CrossRef]

7. Kroll, L.E.; Lampert, T. Unemployment, Social Support and Health Problems: Results of the GEDA Study in Germany, 2009. Dtsch. Arztebl. Int. 2011, 108, 47-52. [CrossRef]

8. Milner, A.; Krnjacki, L.; Butterworth, P.; LaMontagne, A.D. The Role of Social Support in Protecting Mental Health When Employed and Unemployed: A Longitudinal Fixed-Effects Analysis Using 12 Annual Waves of the HILDA Cohort. Soc. Sci. Med. 2016, 153, 20-26. [CrossRef]

9. Lim, A.Y.; Lee, S.-H.; Jeon, Y.; Yoo, R.; Jung, H.-Y. Job-Seeking Stress, Mental Health Problems, and the Role of Perceived Social Support in University Graduates in Korea. J. Korean Med. Sci. 2018, 33, e149. [CrossRef]

10. Pow, J.; King, D.B.; Stephenson, E.; DeLongis, A. Does Social Support Buffer the Effects of Occupational Stress on Sleep Quality among Paramedics? A Daily Diary Study. J. Occup. Health Psychol. 2017, 22, 71-85. [CrossRef]

11. Canivet, C.; Bodin, T.; Emmelin, M.; Toivanen, S.; Moghaddassi, M.; Östergren, P.-O. Precarious Employment Is a Risk Factor for Poor Mental Health in Young Individuals in Sweden: A Cohort Study with Multiple Follow-Ups. BMC Public Health 2016, 16, 687. [CrossRef]

12. Benach, J.; Vives, A.; Amable, M.; Vanroelen, C.; Tarafa, G.; Muntaner, C. Precarious Employment: Understanding an Emerging Social Determinant of Health. Annu. Rev. Public Health 2014, 35, 229-253. [CrossRef]

13. Benach, J.; Vives, A.; Tarafa, G.; Delclos, C.; Muntaner, C. What Should We Know about Precarious Employment and Health in 2025? Framing the Agenda for the next Decade of Research. Int. J. Epidemiol. 2016, 45, 232-238. [CrossRef] [PubMed]

14. Buchholz, S.; Hofäcker, D.; Mills, M.; Blossfeld, H.-P.; Kurz, K.; Hofmeister, H. Life Courses in the Globalization Process: The Development of Social Inequalities in Modern Societies. Eur. Sociol. Rev. 2009, 25, 53-71. [CrossRef]

15. Matilla-Santander, N.; Ahonen, E.; Albin, M.; Baron, S.; Bolíbar, M.; Bosmans, K.; Burström, B.; Cuervo, I.; Davis, L.; Gunn, V.; et al. COVID-19 and Precarious Employment: Consequences of the Evolving Crisis. Int. J. Health Serv. 2021, 51, 226-228. [CrossRef] [PubMed]

16. Mirowsky, J.; Ross, C.E. Social Patterns of Distress. Annu. Rev. Sociol. 1986, 12, 23-45. [CrossRef]

17. Siegrist, J.; Theorell, T. Socio-Economic Position and Health. The Role of Work and Employment. In Social Inequalities in Health: New Evidence and Policy Implications; Siegrist, J., Marmot, M., Eds.; Oxford University Press: Oxford, UK, 2006; ISBN 978-0-19-856816-2. 
18. Muntaner, C.; Solar, O.; Vanroelen, C.; Martínez, J.M.; Vergara, M.; Santana, V.; Castedo, A.; Kim, I.-H.; Benach, J. Unemployment, Informal Work, Precarious Employment, Child Labor, Slavery, and Health Inequalities: Pathways and Mechanisms. Int. J. Health Serv. 2010, 40, 281-295. [CrossRef]

19. Clarke, M.; Lewchuk, W.; de Wolff, A.; King, A. “This Just Isn't Sustainable": Precarious Employment, Stress and Workers' Health. Int. J. Law Psychiatry 2007, 30, 311-326. [CrossRef] [PubMed]

20. De_Cuyper, N.; De Witte, H. Job Insecurity and Employability among Temporary Workers: A Theoretical Approach Based on the Psychological Contract. In The Individual in the Changing Working Life; Naswall, K., Hellgren, J., Sverke, M., Eds.; Cambridge University Press: Cambridge, UK, 2008; pp. 88-107. ISBN 978-1-139-47049-0.

21. Lewchuk, W.; Clarke, M.; De Wolff, A. Working Without Commitments: Precarious Employment and Health. Work Employ. Soc. 2008, 22, 387-406. [CrossRef]

22. Sverke, M.; Hellgren, J. The Nature of Job Insecurity: Understanding Employment Uncertainty on the Brink of a New Millennium Appl. Psychol. 2002, 51, 23-42. [CrossRef]

23. Bolíbar, M.; Belvis, F.X.; Jódar, P.; Vives, A.; Méndez, F.; Bartoll-Roca, X.; Pozo, O.J.; Gomez-Gomez, A.; Padrosa, E.; Benach, J.; et al. Precarious Employment and Stress: The Biomedical Embodiment of Social Factors. PRESSED Project Study Protocol. Front. Public Health 2021, 9, 649447. [CrossRef]

24. Marques, E.; Castello, G.; Bichir, R.M. Explorando as associações entre redes pessoais e acesso a bens materiais em duas metrópoles brasileiras. Redes Rev. Hisp. Para Anál. Redes Soc. 2012, 22, 23-49. [CrossRef]

25. McPherson, M.; Smith-Lovin, L.; Cook, J.M. Birds of a Feather: Homophily in Social Networks. Annu. Rev. Sociol. 2001, 27, 415-444. [CrossRef]

26. Harris, K.M.; Schorpp, K.M. Integrating Biomarkers in Social Stratification and Health Research. Annu. Rev. Sociol. 2018, 44, 361-386. [CrossRef] [PubMed]

27. Stephens, M.A.C.; Wand, G. Stress and the HPA Axis: Role of Glucocorticoids in Alcohol Dependence. Alcohol Res. 2012, 34, 468-483.

28. Staufenbiel, S.M.; Penninx, B.W.J.H.; Spijker, A.T.; Elzinga, B.M.; van Rossum, E.F.C. Hair Cortisol, Stress Exposure, and Mental Health in Humans: A Systematic Review. Psychoneuroendocrinology 2013, 38, 1220-1235. [CrossRef]

29. Serwinski, B. Psychosocial Factors and Cortisol Sampled from Hair and Saliva. Ph.D. Thesis, University College London, London, UK, 2017.

30. Staufenbiel, S.M.; Koenders, M.A.; Giltay, E.J.; Elzinga, B.M.; Manenschijn, L.; Hoencamp, E.; van Rossum, E.F.C.; Spijker, A.T. Recent Negative Life Events Increase Hair Cortisol Concentrations in Patients with Bipolar Disorder. Stress 2014, 17, 451-459. [CrossRef]

31. Staufenbiel, S.M.; Penninx, B.W.J.H.; de Rijke, Y.B.; van den Akker, E.L.T.; van Rossum, E.F.C. Determinants of Hair Cortisol and Hair Cortisone Concentrations in Adults. Psychoneuroendocrinology 2015, 60, 182-194. [CrossRef] [PubMed]

32. Vives, A.; Amable, M.; Ferrer, M.; Moncada, S.; Llorens, C.; Muntaner, C.; Benavides, F.G.; Benach, J. The Employment Precariousness Scale (EPRES): Psychometric Properties of a New Tool for Epidemiological Studies among Waged and Salaried Workers. Occup. Environ. Med. 2010, 67, 548-555. [CrossRef] [PubMed]

33. Broadhead, W.E.; Gehlbach, S.H.; de Gruy, F.V.; Kaplan, B.H. The Duke-UNC Functional Social Support Questionnaire. Measurement of Social Support in Family Medicine Patients. Med. Care 1988, 26, 709-723. [CrossRef] [PubMed]

34. Bellón Saameño, J.A.; Delgado Sánchez, A.; de Dios Luna del Castillo, J.; Lardelli Claret, P. Validez y fiabilidad del cuestionario de apoyo social funcional Duke-UNC-11. Aten Primaria 1996, 18, 153-163.

35. Cohen, S.; Kamarck, T.; Mermelstein, R. A Global Measure of Perceived Stress. J. Health Soc. Behav. 1983, 24, 385-396. [CrossRef] [PubMed]

36. Gomez-Gomez, A.; Pozo, O.J. Determination of Steroid Profile in Hair by Liquid Chromatography Tandem Mass Spectrometry. J. Chromatogr. A 2020, 1624, 461179. [CrossRef] [PubMed]

37. Johnson, P.O.; Neyman, J. Tests of Certain Linear Hypotheses and Their Application to Some Educational Problems. Stat. Res. Mem. 1936, 1, 57-93.

38. White, C.R. Allometric Analysis beyond Heterogeneous Regression Slopes: Use of the Johnson-Neyman Technique in Comparative Biology. Physiol. Biochem. Zool. Ecol. Evol. Approaches 2003, 76, 135-140. [CrossRef]

39. Stalder, T.; Steudte, S.; Alexander, N.; Miller, R.; Gao, W.; Dettenborn, L.; Kirschbaum, C. Cortisol in Hair, Body Mass Index and Stress-Related Measures. Biol. Psychol. 2012, 90, 218-223. [CrossRef]

40. Hayes, A.F. Introduction to Mediation, Moderation, and Conditional Process Analysis, Second Edition: A Regression-Based Approach, 2nd ed.; Guilford Press: New York, NY, USA, 2018; ISBN 978-1-4625-3465-4.

41. Long, J.A. Interactions: Comprehensive, User-Friendly Toolkit for Probing Interactions. R Package Version 1.1. 0 2019. Available online: https:/ / interactions.jacob-long.com/ (accessed on 27 December 2021).

42. Peña, E.A.; Slate, E.H. Global Validation of Linear Model Assumptions. J. Am. Stat. Assoc. 2006, 101, 341-354. [CrossRef]

43. Lakey, B.; Cronin, A. Chapter 17-Low Social Support and Major Depression: Research, Theory and Methodological Issues. In Risk Factors in Depression; Dobson, K.S., Dozois, D.J.A., Eds.; Elsevier: San Diego, CA, USA, 2008; pp. 385-408. ISBN 978-0-08-045078-0

44. Glaser, D.N.; Tatum, B.C.; Nebeker, D.M.; Sorenson, R.C.; Aiello, J.R. Workload and Social Support: Effects on Performance and Stress. Hum. Perform. 1999, 12, 155-176. [CrossRef] 
45. Kaufmann, G.M.; Beehr, T.A. Interactions between Job Stressors and Social Support: Some Counterintuitive Results. J. Appl. Psychol. 1986, 71, 522-526. [CrossRef]

46. Kokoroko, E.; Sanda, M.A. Effect of Workload on Job Stress of Ghanaian OPD Nurses: The Role of Coworker Support. Saf. Health Work 2019, 10, 341-346. [CrossRef]

47. Liu, C.; Huang, N.; Ahmed, F.; Shahid, M.; Wang, X.; Guo, J. The Reverse Buffering Effects of Social Support on the Relationships between Stresses and Mental Health: A Survey of Chinese Adults during the COVID-19 Lockdown. Eur. J. Psychotraumatol. 2021, 12, 1952777. [CrossRef] 